\title{
Diagnosis and management of eosinophilic asthma: a US perspective
}

\author{
This article was published in the following Dove Press journal: \\ Journal of Asthma and Allergy \\ II April 2014 \\ Number of times this article has been viewed
}

\author{
Hannah H Walford ${ }^{1,2}$ \\ Taylor A Doherty' \\ 'Department of Medicine, \\ ${ }^{2}$ Department of Pediatrics, University \\ of California, La Jolla, CA, USA
}

\begin{abstract}
Eosinophilic asthma is now recognized as an important subphenotype of asthma based on the pattern of inflammatory cellular infiltrate in the airway. Eosinophilic asthma can be associated with increased asthma severity, atopy, late-onset disease, and steroid refractoriness. Induced sputum cell count is the gold standard for identifying eosinophilic inflammation in asthma although several noninvasive biomarkers, including fractional exhaled nitric oxide and periostin, are emerging as potential surrogates. As novel therapies and biologic agents become increasingly available, there is an increased need for specific phenotype-directed treatment strategies. Greater recognition and understanding of the unique immunopathology of this asthma phenotype has important implications for management of the disease and the potential to improve patient outcomes. The present review provides a summary of the clinical features, pathogenesis, diagnosis, and management of eosinophilic asthma.
\end{abstract}

Keywords: asthma, eosinophil, allergy, Th2, IL-4, IL-13

\section{Introduction}

An estimated $8.4 \%$ of the US population has a diagnosis of asthma and approximately $10 \%-20 \%$ of those individuals remain poorly controlled despite high-dose inhaled corticosteroids and long-acting beta-agonists. ${ }^{1,2}$ Asthma has been traditionally defined as a chronic respiratory disease characterized by reversible airflow obstruction, bronchial hyperresponsiveness, and airway inflammation. It is now recognized that the term "asthma" actually represents a heterogeneous collection of respiratory diseases with distinct phenotypes originating from the complex interplay between individual genetic and environmental factors. Therefore, rather than a "one size fits all" approach to asthma treatment, evidence is now emerging that unique pathophysiologic mechanisms may drive airway inflammation in each subtype of the disease and alter the response to conventional therapies. By better identifying asthma phenotypes, we may be able to use more targeted therapies, both existing and novel, to achieve asthma control in patients who have failed standard treatment.

Phenotype-targeted therapies are especially important for patients with severe refractory asthma, who represent less than $10 \%$ of all asthmatics, but are responsible for a disproportionate share of morbidity and health care costs related to the disease. ${ }^{3}$ Several strategies have been proposed to categorize severe asthma phenotypes based on characteristics such as patient age, disease onset, corticosteroid resistance, chronic airflow obstruction, or type of cellular infiltrate in the airway lumen or lung tissue., A newly proposed approach to asthma classification is based on "endotypes" that represent specific cellular patterns along with clinical characteristics within each
Correspondence: Taylor A Doherty Department of Medicine, University of California San Diego, Biomedical Sciences Building, Room 5080, 9500 Gilman Drive, La Jolla, CA 92093-0635, USA

Tel +l 8588227563

Fax +l 8585342110

Email tdoherty@ucsd.edu 
patient subgroup. ${ }^{6}$ Analysis of induced sputum samples has allowed for determination of inflammatory phenotypes according to granulocytic composition, namely eosinophilic, neutrophilic, mixed granulocytic, or paucigranulocytic.? Interestingly, patients with severe adult-onset asthma can be divided into a neutrophilic inflammatory phenotype or have eosinophilic inflammation that is unresponsive to high-dose steroids. ${ }^{89}$ This discussion focuses on our current understanding of "eosinophilic asthma" as a distinct asthma phenotype in US populations, with special attention paid to pathophysiology, diagnostic evaluation, and management.

\section{Eosinophils in the pathogenesis of asthma}

Eosinophils have long been implicated in the pathogenesis of asthma. Post mortem pathologic studies of patients who have died from asthma attacks show airway mucosa infiltrated with activated eosinophils. ${ }^{10}$ Over 20 years ago, Bousquet et al published their findings demonstrating that chronic asthmatics had an increase in eosinophils in peripheral blood and bronchoalveolar lavage fluid, along with lung biopsy specimens that correlated with the severity of asthma. ${ }^{11}$ The presence of eosinophils in the airway lumen, as identified by sputum cell counts, has since been shown to be predictive of loss of asthma control after discontinuation of inhaled corticosteroids. ${ }^{12,13}$ Further, the persistence of eosinophils in sputum despite high doses of corticosteroids may also be a marker of disease severity. ${ }^{14}$ Generally, the eosinophilic phenotype is associated with a good response to corticosteroids and to T-helper type 2 (Th2) targeted therapy, such as anti-interleukin (IL)-5 treatments discussed below. ${ }^{15-17}$

Eosinophilic asthma has classically been associated with allergic sensitization and a Th2-dominant inflammatory response. The Th2-driven phenotype arises from dysregulated innate and adaptive immune responses. During allergic sensitization, inhaled allergens are taken up by antigen-presenting dendritic cells in the airway and presented to T-cells. ${ }^{18}$ The cytokine milieu leads to T-helper cell differentiation and production of IL-4, IL-5, and IL-13, resulting in immunoglobulin (Ig)E class switching, eosinophil recruitment, mucus production, airway hyperresponsiveness, and remodeling features. ${ }^{19,20} \mathrm{IL}-5$ is a critical cytokine for eosinophil generation in the bone marrow, as well as eosinophil recruitment, activation, and survival. Upon airway allergen re-exposure, allergen cross-linking of $\operatorname{IgE}$ on mast cells and basophils results in inflammatory degranulation with the release of preformed and newly synthesized mediators including histamine, cysteinyl leukotrienes, prostaglandin D2, and chemokines, resulting in acute allergic reactions with vasodilation, edema, and bronchospasm. This is followed by the influx of activated cells, including eosinophils and cytokine-producing $\mathrm{T}$ cells into the airway, contributing to airway hyperresponsiveness that characterizes an asthma exacerbation.

In addition to the classic allergen-mediated Th2 paradigm, innate immune stimuli such as environmental factors, air pollution, weather changes (eg, thunderstorms), and viral infections may be capable of eliciting Th2 responses associated with eosinophilia. ${ }^{21,22}$ Cytokines derived from bronchial epithelium, including thymic stromal lymphoprotein, IL-25, and IL-33, are released in response to an allergen, viral antigen, or mucosal injury, and may drive Th2 polarization as well as activation of innate type 2 pathways. ${ }^{23}$ Thymic stromal lymphopoietin (TSLP) induced by respiratory syncytial virus has been shown to promote a type 2 response to infection by promoting a dendritic cell/CD4+ Th2 cell activation pathway through OX40/OX40 ligand interactions. ${ }^{24,25}$ TSLP also induces dendritic cells to release chemokine ligand 13 (human monocyte chemoattractant protein-4) and chemokine ligand 17 (thymus and activation regulated chemokine), which recruit Th2 cells via chemokine receptor $4 .{ }^{26}$ Other cell types including basophils, natural killer T-cells, and group 2 innate lymphoid cells are also important sources of type 2 cytokines, which regulate eosinophil influx into the lungs. Despite the significant complexity of redundant and nonredundant inflammatory pathways in asthma, critical steps that lead to eosinophil influx into the airway have been elucidated.

Recruitment of eosinophils into the airway in allergic asthma is mediated by the coordinated action of cytokines and chemokines including IL-5, IL-13, eotaxins, and the adhesion molecules P-selectin and vascular cell adhesion molecule-1. ${ }^{27}$ Maturation of eosinophils from myeloid precursors in the bone marrow is promoted by IL-5, IL-3, and granulocyte macrophage-colony stimulating factor (GM-CSF).$^{28}$ Eosinophils then circulate in the peripheral blood and are normally present in peripheral tissue and respiratory mucosa, but increase in number in the setting of acute inflammation. IL-5 is a potent eosinophil activator and facilitates recruitment into tissues that is further enhanced by eotaxins and chemokine ligand 5 (also known as RANTES) released by immune and airway resident cells. ${ }^{29}$ GM-CSF is upregulated after allergen challenge and is localized to alveolar macrophages and lymphocytes as well as eosinophils themselves, suggesting an autocrine pathway. ${ }^{30,31}$ Other chemoattractants for eosinophils include complement product $\mathrm{C} 5 \mathrm{a}$ and the lipid mediators platelet-activating factor and 


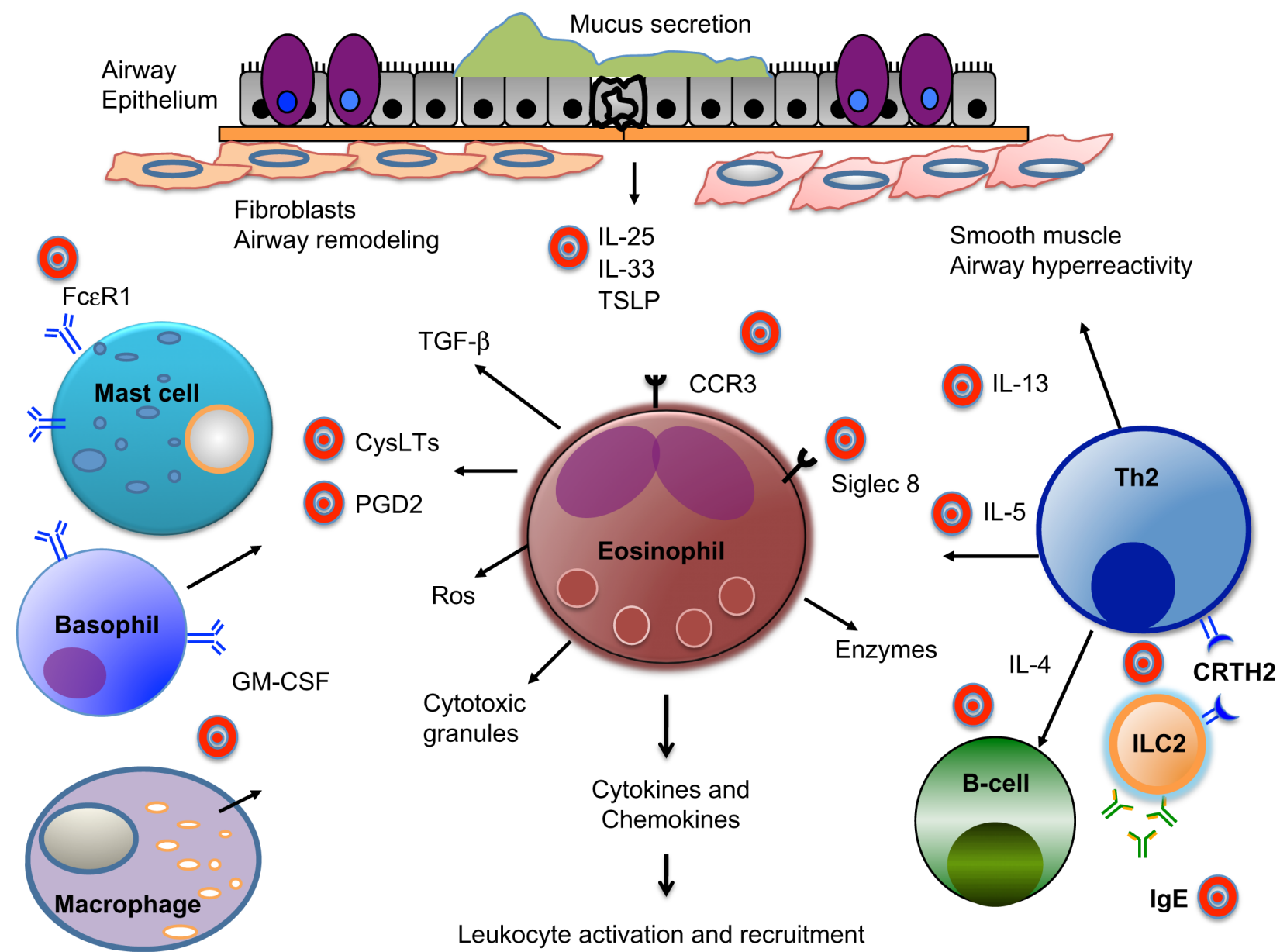

Figure I Schematic of eosinophils in airway inflammation and therapeutic targets. In response to allergens, viruses, or mucosal injury, airway epithelial cells produce cytokines, including IL-25, IL-33, and TSLP, which promote differentiation of Th2 cells, as well as activation of mast cells, macrophages, and type 2 innate lymphoid cells. IL-4 and IL-13 produced by Th2 and other cells results in eotaxin production, B-cell IgE class switching, airway hyperresponsiveness, and mucus secretion. IL-5 stimulates bone marrow eosinophil generation, and mediates recruitment, activation, and survival of eosinophils. GM-CSF produced by alveolar macrophages and eosinophils contributes to maturation and survival of eosinophils. Eosinophils release major basic protein, ROS, and enzymes, as well as Th2 cytokines and inflammatory lipid mediators including cysteinyl leukotrienes and prostaglandin D2. These products result in recruitment and activation of immune and structural cells. Further, production of Th2 cytokines and growth factors, such as TGF- $\beta$, contribute to features of airway remodeling in chronic asthma. A number of therapeutic targets (depicted by bullseyes) have been identified for eosinophilic asthma and are currently under investigation.

Abbreviations: CRTH2, chemoattractant receptor homologous Th2; CystLTs, cysteinyl leukotrienes; GM-CSF, granulocyte macrophage-colony stimulating factor; IL, interleukin; ILC2, innate lymphoid cell type 2; IgE, immunoglobulin E; PGD2, prostaglandin D2; ROS, reactive oxygen species; Siglec-8, sialic acid binding Ig-like lectin 8; Th2, T-helper type 2; TGF- $\beta$, transforming growth factor beta; TSLP, thymic stromal lymphoprotein.

leukotriene B4. Upon migration from the blood, eosinophils bind to endothelial cells expressing E-selectin and vascular cell adhesion molecule-1 (ligand for VLA-4 integrin), which facilitate migration into the tissue. ${ }^{32}$ Eosinophil infiltration also depends on chemokine ligand 11 (eotaxin-1), which is produced by the respiratory epithelium and binds to the eosinophil chemokine receptor 3 (CCR3). ${ }^{33}$

Once activated, eosinophils secrete their granule contents which consist of four principal proteins: major basic protein, eosinophilic cation protein, eosinophilic-derived neurotoxin, and eosinophil peroxidase. Eosinophils also release inflammatory lipid mediators, including cysteinyl leukotrienes C4 and D4, platelet-activating factor, and prostaglandin D2 which further propagate the allergic response. Murine models have suggested that IL-5 and eosinophils may also promote airway remodeling via eosinophil expression of transforming growth factor- $\beta .{ }^{34}$ Other important growth factors and Th 2 cytokines that may contribute to airway remodeling in asthma include vascular endothelial growth factor, IL-9, and IL-13, which may also be produced by eosinophils. ${ }^{20}$ These pathways along with therapeutic targets are highlighted in Figure 1.

\section{Defining eosinophilic asthma}

Eosinophilic asthma has been defined as a distinct phenotype of asthma that is associated with tissue and sputum eosinophilia, thickening of the basement membrane zone, and often 
by corticosteroid responsiveness. ${ }^{15,35}$ The advent of sputum induction has allowed for improved classification of airway inflammation, identification of asthma phenotypes, and drawing associations with other biomarkers. ${ }^{35}$ Sputum cell counts defining eosinophilic asthma vary between studies ranging from $1 \%$ to $3 \%$. Importantly, normalization of induced sputum eosinophil counts has also been shown to be an effective strategy for preventing severe asthma exacerbations and hospitalizations, and suggests clinical utility in ongoing asthma management. ${ }^{36}$

In several studies, the number of eosinophils in induced sputum has been detected at higher levels in patients with more severe asthma. ${ }^{37-39}$ Woodruff et al demonstrated that the percentage of eosinophils in induced sputum was independently associated with more severe airflow obstruction and methacholine reactivity in over 200 subjects. ${ }^{37}$ Another study stratified asthmatics into four subgroups based on sputum inflammatory cell type and observed the highest degree of airway hyperresponsiveness to mannitol in the purely eosinophilic group. ${ }^{39}$ Although these studies further implicate the eosinophil in a subset of severe asthmatics, additional investigations suggest that there may be a dissociation between airway hyperresponsiveness and eosinophilia. ${ }^{40}$

Early pathologic studies by Wenzel et al led to the description of subgroups of severe asthmatics on the basis of the presence or absence of eosinophils. ${ }^{8}$ Miranda et al reported that the majority of severe asthmatics had elevated airway eosinophils despite chronic treatment with highdose oral steroids. ${ }^{41}$ However, they found that far fewer patients who developed asthma early in life demonstrated tissue eosinophilia, as compared with the group with lateonset asthma (36\% early-onset versus 63\% late-onset). Surprisingly, there was evidence of persistent eosinophilia in the late-onset asthmatics despite a lower rate of skin prick sensitization. However, in the early onset group, the presence of eosinophils on biopsy was associated with an increased prevalence of near-fatal events (intubations). This study highlights the association between numbers of eosinophils and severity of asthma in patients with corticosteroid-refractory disease and suggests discordance between atopy and eosinophilic airway disease in a subset of patients.

Importantly, ten Brinke et al challenged the notion of steroid-refractory eosinophilic asthma in a follow-up study in which sputum eosinophils were eliminated in nearly all severe asthmatics using high doses of parenteral triamcinolone. ${ }^{42}$ These results suggest that the persistence of eosinophilia was more likely due to inadequate therapy rather than a lack of steroid response. However, further studies have supported an association between sputum eosinophils and severe adultonset asthma. ${ }^{9}$ These individuals are largely nonatopic, yet have persistent eosinophilic airway inflammation, further supporting a distinct underlying mechanism of eosinophilic inflammation apart from allergy.

Notably, eosinophilic asthma is very prevalent in individuals with nonsevere disease. Berry et al studied subjects with mild to moderate asthma and stratified them by the presence or absence of eosinophils in their sputum. ${ }^{15}$ They found that subjects with eosinophilia had increased thickness of the subepithelial basement membrane zone and improved short-term response to treatment with inhaled corticosteroids. In addition, they found higher numbers of T-lymphocytes, mast cells, and macrophages in the subgroup of subjects with severe asthma and eosinophilia.

In support of distinct subtypes of eosinophilic asthma, airway infiltration of eosinophils is present in other respiratory conditions, including allergic bronchopulmonary aspergillosis, Churg-Strauss syndrome, aspirin-exacerbated respiratory disease, and eosinophilic bronchitis. Eosinophilic bronchitis differs from eosinophilic asthma in several ways. Clinically, patients with eosinophilic bronchitis have symptoms of cough, but in contrast with asthmatics, have normal lung function and lack airway responsiveness. ${ }^{43}$ Further, although both conditions are associated with eosinophilic infiltration in the airways, they have distinct immunohistochemical features. Biopsy specimens from patients with asthma, as compared with eosinophilic bronchitis, reveal a striking increase in the number of mast cells in smooth muscle bundles. ${ }^{44}$ Further, vascular endothelial growth factor levels and airway permeability are increased in asthma, but not in eosinophilic bronchitis. ${ }^{45}$ Vascular endothelial growth factor is believed to increase vascular permeability, promote angiogenesis, and play a role in several aspects of airway remodeling. The principal source of vascular endothelial growth factor in the airway is not entirely clear, but may include eosinophils, macrophages, epithelial cells, and smooth muscle. ${ }^{20}$ Thus, the presence and activity of other inflammatory cells in conjunction with eosinophils may underlie a severe asthma endotype.

\section{Diagnostic evaluation of eosinophilic asthma}

Traditional guideline-based treatment decisions in asthma target symptoms and lung function, but specific therapies targeting the underlying inflammatory process may be needed in a subset of patients. Sputum eosinophils are an accurate reflection 
of Th2-dominant mechanisms in uncontrolled asthma, and eosinophilic asthma is generally defined by $>1 \%-3 \%$ of eosinophils. Induced sputum is the most reliable measure of inflammatory cell counts although quantitative sputum cell counts are difficult to obtain in routine practice and require access to specific laboratories with trained personnel. The utility of several alternative markers of eosinophilic inflammation are currently being investigated including peripheral blood eosinophil counts, fractional exhaled nitric oxide (FeNO), serum IgE, and periostin levels.

Peripheral blood eosinophil counts are easily obtained and widely available, but lack both specificity and sensitivity. Although few asthmatics may demonstrate an increase in blood eosinophils, ${ }^{46}$ in those asthmatics with peripheral eosinophilia, there is a suggested correlation with severity of asthma symptoms and an inverse correlation in pulmonary function as measured by forced expiratory volume in one second $\left(\mathrm{FEV}_{1}\right) .{ }^{47}$ Nonetheless, blood eosinophil counts have not been shown to correlate reliably with elevated sputum eosinophils in asthma. Hastie et al recently evaluated multiple variables including exhaled nitric oxide levels, $\mathrm{FEV}_{1}$, total IgE, and blood eosinophil counts in predicting asthma phenotype. ${ }^{48}$ The authors demonstrated that levels of blood eosinophils $>300 / \mu \mathrm{L}$ had a positive predictive value of only $50 \%$ in identifying an eosinophilic asthma phenotype based on sputum eosinophils of $>2 \%$. Further, longitudinal studies examining sputum cell counts in consecutive exacerbations showed significant heterogeneity in the type of cellular inflammation within the same individuals. ${ }^{49}$ Taken together, these findings suggest that peripheral blood eosinophilia may be a marker of disease severity in asthma, but does not correlate consistently with sputum eosinophilia.

As discussed, eosinophilic asthma can be associated with Th2-mediated allergic disease and allergen sensitization, especially in earlier onset disease. Surprisingly, there does not appear to be a correlation with total serum IgE, as demonstrated in a study by Good et al in which bronchoscopy was used to assess asthma phenotypes. ${ }^{50}$ The authors demonstrated a lack of correlation between total IgE levels and the presence of eosinophils in bronchoalveolar lavage fluid or biopsy specimens, despite the fact that over $80 \%$ of patients with evidence of eosinophils had positive skin testing. Thus, although IgE levels may be helpful in the diagnosis of allergic bronchopulmonary aspergillosis, with features of asthma and eosinophilia, the total $\operatorname{IgE}$ has little utility in evaluation of most patients with asthma.

Nitric oxide is a reactive molecule synthesized by nitric oxide synthase expressed on cells within the airway epithelium. FeNO as measured by breath tests is often used as a noninvasive marker of airway inflammation in asthma. In contrast with bronchoscopy and sputum induction, FeNO measurement is rapid, simple, and noninvasive. There is growing evidence that FeNO measurement may be useful as a clinical tool in managing asthma and guiding therapy; however, conflicting studies have resulted in some controversy about the utility of FeNO. ${ }^{51-53}$ Smith et al studied more than 90 asthmatics and found that FeNO was a useful tool in stepping down inhaled corticosteroid therapy. ${ }^{54}$ Tseliou et al also demonstrated that FeNO levels $>19$ parts per billion predicted sputum eosinophilia with a sensitivity of $78 \%$ and a specificity of $73 \%$ in patients with moderate to severe asthma, some of whom were prednisone-dependent. ${ }^{55}$ On the other hand, Nair et al reported a lack of correlation between sputum eosinophil percentages and FeNO levels in patients with prednisone-dependent asthma who participated in a clinical trial with the anti-IL-5 antibody mepolizumab. ${ }^{17}$

Periostin is an extracellular matrix protein upregulated by IL-13 and has been shown to facilitate allergen-induced eosinophil recruitment to the lungs by mediating eosinophil adhesion to fibronectin. ${ }^{56}$ In murine models, periostindeficient mice challenged with Aspergillus fumigatus demonstrated a decrease in airway eosinophilia as compared with wild-type mice, but no change in tissue lymphocytes or neutrophils. ${ }^{56}$ Further, periostin has been shown to induce survival of lung cancer cells through the Akt/PKB pathway, and perhaps periostin could promote the survival of eosinophils, although this has not been tested. ${ }^{57}$ Overall, periostin has potential as a systemic biomarker for identification of airway eosinophilia in asthmatics, possibly due to its role in induction of tissue of eosinophilia.

Using a logistic regression model including age, sex, body mass index, IgE levels, blood eosinophils, FeNO levels, and serum periostin levels in 59 patients with severe asthma, Jia et al recently reported that serum periostin was the best predictor of airway eosinophilia. ${ }^{58} \mathrm{~A}$ serum periostin level $>25 \mathrm{ng} / \mathrm{mL}$ had a positive predictive value of $93 \%$ and a negative predictive value of $37 \%$ for sputum eosinophils ( $>3 \%$ ) or tissue eosinophilia. Further, in a recent anti-IL-13 treatment study, patients with higher periostin levels had greater improvements in $\mathrm{FEV}_{1}$ suggesting that periostin levels may be predictive of therapeutic response. ${ }^{59}$ While the airway epithelium can be stimulated by IL-4 and IL-13 to secrete periostin, ${ }^{60}$ the precise role of periostin in asthma is not clear. Apart from a role in eosinophilia, animal models suggest that periostin may be involved in airway remodeling via transforming growth factor- $\beta$ and 
may also have a protective role in allergen-induced airway hyperresponsiveness. ${ }^{61}$

A recent study by Kulkarni et al evaluated the use of eosinophil protein in airway macrophages as a noninvasive biomarker of eosinophilic airway inflammation. ${ }^{62}$ The burden of tissue eosinophilia is a balance between the eosinophilic influx and clearance by airway macrophages. Therefore, they assessed eosinophil protein levels by means of flow cytometry, immunofluorescence, and cytoplasmic hue change after macrophage ingestion of apoptotic eosinophils. They concluded that airway macrophage eosinophil protein content was increased in subjects with severe asthma and may have clinical utility in predicting ongoing eosinophilic inflammation and success of weaning from corticosteroids.

\section{Therapeutics in eosinophilic asthma}

Current management of eosinophilic asthma begins with standard guideline-based therapy, including inhaled corticosteroids and bronchodilators which have been reviewed extensively elsewhere. ${ }^{63}$ Generally, the presence of eosinophils has been associated with responsiveness to corticosteroids although some patients with eosinophilic asthma have been reported to be "steroid-refractory". Specific therapeutics targeting inflammatory mediators are currently under investigation in clinical trials for patients who have failed standard therapy and remain steroid-dependent or refractory.

\section{Agents targeting corticosteroid resistance}

Several mechanisms that may account for corticosteroidresistant asthma have been reported including activation of p38 mitogen-activated protein kinase and inflammatory genes regulated through transcription factor nuclear factor- $\kappa \mathrm{B} .{ }^{64}$ P38 mitogen-activated protein kinase is important in the activation of GATA3, the master Th2 cytokine transcription factor. ${ }^{65}$ Small molecule p38 inhibitors have been demonstrated to attenuate asthmatic features in mice. ${ }^{65}$ However, clinical trials in humans for the treatment of inflammatory disease have been associated with substantial systemic side effects. ${ }^{66}$ Phosphoinositide 3-kinase (PI3K) also regulates inflammatory pathways, and activation of the isozyme $\mathrm{PI} 3 \mathrm{~K} \delta$ by oxidative stress may decrease corticosteroid responsiveness through reductions in histone deacetylase 2 , an enzyme targeted by theophylline. ${ }^{67}$ Other mechanisms for steroidrefractory asthma may include increased expression of the alternatively spliced variant of the glucocorticoid receptor and increased production of macrophage migratory inhibitory factor, which may block the anti-inflammatory effects of corticosteroids. ${ }^{67,68}$

\section{Biologic therapies}

Availability of biologic agents for the treatment of asthma began with the approval of an anti-IgE monoclonal antibody, omalizumab (Xolair ${ }^{\circledR}$; Genentech/Novartis, Basel, Switzerland), for the treatment of uncontrolled disease. Drugs targeting specific Th2 cytokines, including monoclonal antibodies against IL-5 and IL-13, have also shown promise in the treatment of refractory eosinophilic asthma. ${ }^{69}$ As data accumulate supporting patient-specific and phenotype-directed therapeutic responses, use of these agents may reduce the burden of disease for those with refractory symptoms despite current treatments. However, the cost of such agents may preclude their widespread use, although reductions in emergency room visits and hospitalizations may outweigh the expense of therapy.

\section{Omalizumab}

Omalizumab is a recombinant humanized monoclonal antibody (IgG1) that binds to the Fc portion of IgE that recognizes its high-affinity receptor (FceR1) on the surface of mast cells and basophils, resulting in receptor downregulation and inhibition of inflammatory mediator release. ${ }^{70}$ Several large-scale randomized controlled trials now support the therapeutic efficacy of subcutaneously administered omalizumab as add-on therapy for severe persistent allergic asthma. ${ }^{71-77}$ In asthmatic patients inadequately controlled despite highdose inhaled corticosteroids and long-acting beta-agonist therapy, omalizumab significantly reduced the rate of severe exacerbations and emergency visits. ${ }^{71}$ Data combined from seven randomized controlled trials indicated that total IgE was the only predictor of response to therapy. ${ }^{78}$ However, allergic sensitization to aeroallergens by skin prick testing was a key inclusion criterion in several of these studies. ${ }^{71-74}$

IgE has a central role in the pathophysiology of allergic responses and omalizumab attenuates both the early-phase and late-phase responses to inhaled allergens in patients with asthma. ${ }^{79}$ While total serum IgE levels do not correlate diagnostically with the degree of tissue eosinophilia, treatment with anti-IgE therapy has been shown to be efficacious and reduce airway and blood eosinophils. ${ }^{80-82}$ One of the initial studies in asthmatics treated with omalizumab demonstrated a significant reduction in eosinophils in induced sputum and airway tissue ( 8.0 at baseline compared with 1.5 post-treatment). ${ }^{82}$ A later report showed that 16 weeks of treatment decreased blood eosinophils from $6.2 \%$ 
at baseline to $1.3 \% .{ }^{81}$ Therefore, while total serum $\mathrm{IgE}$ is not useful as a diagnostic marker for eosinophilic asthma, total serum IgE levels should be obtained if considering anti-IgE therapy.

One explanation for the apparent paradox that antiIgE therapy is useful for treatment in eosinophilic asthma despite $\operatorname{IgE}$ levels not being predictive of response may be related to downregulation of FceR1 on the surface of mast cells, basophils, and dendritic cells by anti-IgE. A reduction in FceR1-expressing cells limits allergen-induced IgE-mediated responses, preventing cytokine release and eosinophil recruitment into the airway. ${ }^{83}$ Additionally, treatment with anti-IgE may lead to decreased levels of airway dendritic cells ${ }^{84}$ resulting in a reduction in Th2 differentiation and the Th2 cytokines necessary for survival and recruitment of eosinophils. Therefore, while total serum IgE may not be predictive of eosinophilic asthma or clinical response, omalizumab has been shown to have an important role in asthma management and reduces airway eosinophils.

Interestingly, Noga et al have demonstrated that omalizumab may also have proapoptotic effects on eosinophils. ${ }^{79}$ In a study of 19 patients with allergic asthma, markers of eosinophil apoptosis (Annexin V) were significantly increased in patients who had received 12 weeks of omalizumab as compared with placebo. The authors also showed a reduction in IL-2, IL-13, and GM-CSF+ lymphocytes in the omalizumab group. Reduction in levels of mast cell mediators that promote eosinophil survival may have led to the apoptosis of eosinophils in omalizumab-treated individuals. Notably, omalizumab has also been found to be a steroidsparing agent in chronic eosinophilic pneumonia, a disease characterized by bilateral pulmonary infiltrates and marked accumulation of eosinophils in bronchoalveolar lavage fluid and blood. ${ }^{85}$ Thus, the effects of anti-IgE therapy on lung eosinophilia have provided further insight into the mechanisms of allergic inflammation, which may lead to improved phenotype-specific treatment.

\section{Targeting IL-5}

IL-5 plays a critical role in promoting eosinophil growth, differentiation, recruitment, and activation in tissues. Early reports demonstrated increased expression of IL-5 in bronchoalveolar lavage fluid and bronchial biopsies from patients with asthma. ${ }^{86}$ Additionally, IL-5 messenger RNA (mRNA) was shown to be upregulated in the bronchial mucosa after allergen challenge, and levels correlated with disease activity. ${ }^{87}$ In animal models, airway eosinophil recruitment and airway hyperresponsiveness in response to allergen challenge were reduced after anti-IL-5 treatment. ${ }^{88}$ Thus, there is ample rationale for targeting IL-5 in human asthma to specifically reduce eosinophil maturation, migration, and survival, which may contribute to multiple aspects of the pathogenesis of asthma.

Mepolizumab is a humanized noncomplement-fixing monoclonal antibody (IgG1) specific for human IL-5. ${ }^{89}$ Mepolizumab blocks the binding of human IL-5 to the alpha chain of the IL-5 receptor complex expressed on the eosinophil cell surface with high affinity. Anti-IL5 therapy has been shown to induce maturational arrest of bone marrow eosinophil precursors and decrease CD34+IL-5R $\alpha+$ eosinophil progenitors in the bronchial mucosa of atopic individuals. ${ }^{90}$

Early studies examining mepolizumab in the treatment of asthma were somewhat disappointing because they failed to show a significant effect on airway hyperresponsiveness or a late asthmatic reaction after inhaled allergen challenge. ${ }^{91-93}$ These studies may have failed to show a meaningful treatment effect due to the endpoints not being closely associated with eosinophilic airway inflammation as well as the broad inclusion of a heterogeneous study population. Despite this, the early studies did show that a single dose of anti-IL5 decreased blood eosinophils for up to 16 weeks and sputum eosinophils for up to 4 weeks. ${ }^{92}$ Of interest, mepolizumab appears to have a differential effect in various tissues, with nearly complete reduction in blood and sputum eosinophils, but only $55 \%$ reduction in bronchial mucosa. ${ }^{93}$ Flood-Page et al postulated that varying degrees of tissue penetration, altered IL-5 receptor expression, or downregulation could be responsible for these differences. ${ }^{93}$ It is also possible that once recruited into the tissue, airway eosinophils may rely on eotaxins, GM-CSF, or IL-3 for their survival.

Two recent studies suggest that there may be a beneficial effect of mepolizumab in specific groups of patients with eosinophilic asthma. In a double-blind, placebocontrolled study of 61 subjects with refractory eosinophilic asthma and a history of recurrent severe exacerbations, mepolizumab-treated patients showed a significant reduction in exacerbations, as well as improvement in symptom scores after monthly infusions of mepolizumab for one year. ${ }^{16}$ A study by Nair et al enrolled asthmatic patients with persistent sputum eosinophilia despite systemic treatment with prednisone. ${ }^{17}$ The authors showed that monthly intravenous mepolizumab reduced sputum and blood eosinophilia, and had a steroid-sparing effect with a substantial decrease in 
prednisone use in the treatment group. Anti-IL5 therapy also resulted in improved asthma control, $\mathrm{FEV}_{1}$, and quality of life. Importantly, these improvements were maintained for at least 8 weeks after the last infusion. Thus, targeting specific subsets of asthmatics with eosinophilia appears to hold the most promise for anti-IL-5 treatment.

Reslizumab, an IgG4 humanized monoclonal antibody against IL-5, has also been given to patients with poorly controlled eosinophilic asthma. ${ }^{94}$ A recent study showed a significant reduction in sputum eosinophils and improvement in lung function when compared with placebo after 15 weeks of treatment with reslizumab $3 \mathrm{mg} / \mathrm{kg}$ given at monthly intervals. There was also a trend towards a decrease in exacerbations, but the study failed to show improvement in asthma control (as measured by the Asthma Control Questionnaire). The beneficial effects of reslizumab were most pronounced in a subgroup of patients with nasal polyps and in those with the highest levels of blood and sputum eosinophils. Interestingly, in addition to eosinophil levels, the presence of nasal polyposis may identify asthmatic patients who benefit the most from anti-IL-5 therapy, although studies designed to investigate this further are needed.

Lastly, benralizumab is a humanized afucosylated monoclonal antibody targeted against IL-5R $\alpha$ on eosinophils and is currently in Phase II trials. An open Phase I trial in 2010 enrolled 44 subjects with mild asthma to determine safety and effective dosing..$^{95}$ The primary outcome was met at all doses administered with a reduction in blood eosinophil counts to nearly undetectable levels (approximately 10 cells $/ \mathrm{mL}$ ) within 24 hours. This effect persisted for at least 2-3 months in subjects dosed in the $0.03-3 \mathrm{mg} / \mathrm{kg}$ range. In a follow-up Phase II study, Laviolette et al examined the effect of a single $1 \mathrm{mg} / \mathrm{kg}$ dose of benralizumab given intravenously compared with three monthly subcutaneous doses (100 mg or $200 \mathrm{mg}$ ) or placebo in adults with eosinophilic asthma. ${ }^{96}$ The authors demonstrated that the intravenous and subcutaneous routes led to a reduction in eosinophil counts in the airway mucosa and sputum, and nearly complete suppression of eosinophil counts in bone marrow and peripheral blood for up to 28 days after the final dose of benralizumab. Anti-IL-5 therapies undoubtedly hold promise for the treatment of eosinophilic severe asthmatics especially as both approved treatments as well as routine diagnostics to appropriately identify patients become available.

\section{Targeting IL-4 and IL4R $\alpha$}

IL-4 and IL-13 expressed by Th2 cells, mast cells, basophils, and innate lymphoid cells are key cytokines in the pathogenesis of allergic asthma and atopic disease. IL-4 is responsible for many features of asthma, including Th2 differentiation, mucus production, and B cell isotype switching. Both IL-4 and IL-13 signal through two different but overlapping heterodimeric receptors that share the alpha subunit of the IL-4 receptor (IL-4R $\alpha$ ) ${ }^{97}$ Receptor ligation activates a common signal transducer and activator of transcription 6 (STAT-6)-mediated signaling pathway critical to development of the Th2 inflammation characteristic of asthma. Importantly, eotaxins that promote eosinophilic recruitment also depend on IL-4/IL-13 activation of STAT6. Several drugs are now under investigation targeting the IL-4/IL-13/ STAT6 pathway.

The humanized IL-4 monoclonal antibody pascolizumab has been evaluated in animal studies and Phase I/II trials. In a Phase I trial, pascolizumab was well tolerated in adult patients with mild to moderate asthma; however, a subsequent large-scale Phase II trial was discontinued because it failed to show clinical effects in symptomatic patients who were steroid-naïve. ${ }^{98}$ Altrakincept is a recombinant human IL-4R $\alpha$ antagonist, and inhibited airway eosinophilic infiltration and mucus hypersecretion when administered during allergen challenges in a mouse model ${ }^{99}$ In a Phase I/II trial, a single inhalation of the drug improved lung function and asthma symptoms. ${ }^{100}$ Pitrakinra is an antagonist targeting the IL-4/IL-13 cytokine heterodimeric receptor, composed of IL-13R $\alpha 1$ and IL-4R $\alpha$ subunits. When administered by the subcutaneous or inhaled route, pitrakinra inhibited allergeninduced early-phase and late-phase reactions. ${ }^{101}$

Dupilumab, a humanized monoclonal antibody to the IL-4R $\alpha$ subunit, was recently studied by Wenzel et al in a double-blind, placebo-controlled study. ${ }^{102}$ The study enrolled 104 patients with moderate to severe persistent asthma and eosinophilia who were randomized to receive dupilumab $300 \mathrm{mg}$ or placebo subcutaneously once weekly for 12 weeks. The study found a significant improvement in lung function in the treatment group, with an associated reduction in asthma exacerbations when long-acting beta-agonists and inhaled glucocorticoids were withdrawn. Additional findings included significant changes from baseline in Th2-associated biomarkers, including FeNO, chemokine ligand 17 (thymus and activation regulated chemokine), IgE, and chemokine ligand 26 (eotaxin-3) in the dupilumab group at 12 weeks. Blood and sputum eosinophil levels were no different after dupilumab treatment, although there were limited numbers of patients who provided sputum, thus precluding statistical analysis. Overall, targeting IL-4R alpha signaling (which also affects 
IL-13 signaling) appears to be a promising therapeutic strategy in eosinophilic asthma.

\section{Targeting IL- 13}

In mouse models, IL-13 plays a critical role in eosinophil recruitment into the airway in a manner dependent on the synergistic activity of eotaxin and IL-5. ${ }^{103}$ Further, several studies suggest that IL-13 may be responsible for glucocorticoid resistance in asthma. ${ }^{104}$ Animal models using IL-13 blockade strategies have shown reductions in allergeninduced inflammation, airway hyperresponsiveness, and airway remodeling. ${ }^{105,106}$ Therefore, pharmaceuticals targeting this cytokine are currently under investigation in patients with steroid-refractory eosinophilic asthma. A Phase II clinical trial of anrukinzumab, a fully human IL-13 targeted antibody, carried out in mild atopic asthmatics showed a reduction in allergen-induced late asthmatic responses after subcutaneous administration of two doses $(2 \mathrm{mg} / \mathrm{kg})$ separated by 2 weeks. ${ }^{107}$

A recent study evaluated lebrikizumab, a humanized anti-IL-13 monoclonal antibody, in 219 adults with inadequately controlled asthma despite inhaled corticosteroids and long-acting beta-agonists. ${ }^{59}$ The study results showed improvement in $\mathrm{FEV}_{1}$ in the treatment arm after 12 weeks of therapy, with a more pronounced effect in patients with high pretreatment serum periostin levels. Interestingly, in post hoc analysis, elevated FeNO as well as high Th2 markers including peripheral eosinophilia, total $\mathrm{IgE}$, chemokine ligand 13 (human monocyte chemoattractant protein-4) and chemokine ligand 17 (thymus and activation regulated chemokine) levels were also associated with a greater reduction in rates of severe exacerbations in the lebrikizumab group compared with placebo. Another anti-IL-13 antibody, tralokinumab, has also shown efficacy in improving lung function in a Phase II study of patients with moderate to severe asthma. ${ }^{108}$

\section{Other therapies}

Other agents under investigation for the treatment of asthma include antagonists targeting thymic stromal lymphoprotein, IL-25, IL-33, GM-CSF, and chemokine receptor 3 expressed on eosinophils. ${ }^{63}$ Neutralizing antibodies to the innate cytokines IL-25, IL-33, and thymic stromal lymphoprotein demonstrate the ability to attenuate allergic airway inflammation in mice, ${ }^{109-111}$ and antibodies targeting thymic stromal lymphoprotein are currently in development as intravenous therapy for patients with mild atopic asthma (ClinicalTrials.gov identifier: NCT01405963). ${ }^{112}$ Additionally, inhaled antisense oligonucleotides that block the common beta chain of IL-3, IL-5, and GM-CSF receptors together with chemokine receptor 3 have shown a small overall effect in reducing the allergen-induced inflammatory response. ${ }^{113}$ Further, a human monoclonal antibody targeting GM-CSF shown to decrease the survival and activation of eosinophils, is currently in Phase II trials for patients with moderate to severe asthma inadequately controlled by corticosteroids. ${ }^{63,114}$

Therapies targeting inflammatory lipid mediators such as prostaglandin D2, which binds to CRTH2 (chemoattractant homologous receptor expressed on Th2 cells) are also in clinical development. Several studies evaluating the ability of CRTH2 antagonists to block the chemotactic effect of prostaglandin D2 on Th2 cells and eosinophils are now underway. ${ }^{63}$ Induction of eosinophilic apoptosis through the Siglec-8 (sialic acid binding Ig-like lectin 8) receptor by an activating antibody or glycan ligand-conjugated nanoparticles is also a potential therapeutic strategy under investigation. ${ }^{115}$ Finally, it is worth mentioning that therapies blocking tumor necrosis factor- $\alpha$, including etanercept, infliximab, and golimumab, have so far demonstrated mixed results in the treatment of asthma. ${ }^{116,117}$

Finally, bronchial thermoplasty, which applies thermal energy to the bronchial wall to reduce airway smooth muscle hypertrophy, has recently been studied as a potential treatment in severe asthma. ${ }^{118}$ Large clinical trials have showed somewhat mixed results, with small improvements in asthmaspecific quality of life measures and exacerbation rates but an overall increase in hospitalizations. ${ }^{119}$ It is unclear exactly how this procedure affects the structural airways or the release of inflammatory mediators by airway smooth muscle cells, and this procedure has not been specifically evaluated in patients with eosinophilic asthma or other phenotypes. ${ }^{120}$

\section{Summary}

In summary, identification of specific phenotypes of asthma with unique underlying pathophysiologic mechanisms may be particularly important for the treatment of patients with severe asthma. One proposed classification based on distinct patterns of inflammatory cell infiltrate in the airway distinguishes eosinophilic from noneosinophilic subgroups. Traditionally, airway eosinophilic infiltration has been associated with Th2-mediated allergic asthma, but there is now evidence that eosinophils are present in the airways of severe asthmatics without allergic disease. The emergence of novel biologic treatments, including monoclonal antibodies and small molecule inhibitors targeted against IgE, Th2 cytokines, and specific inflammatory 
mediators, has led to an enhanced understanding of the pathogenesis of asthma and highlighted the importance of patient-specific treatment. Development of noninvasive biomarkers is becoming increasingly important for subsets of asthmatic patients, including those with eosinophilic inflammation, as they may predict the response to therapy.

\section{Acknowledgment}

This research was supported by a grant from the National Institutes of Health 1K08AI080938-01A1 and the American Lung Association/American Academy of Allergy, Asthma, and Immunology Allergic Respiratory Diseases Award to TAD.

\section{Disclosure}

The authors report no conflicts of interest in this work.

\section{References}

1. Bateman ED, Boushey HA, Bousquet J, et al; GOAL Inverstigators Group. Can guideline-defined asthma control be achieved? The Gaining Optimal Asthma Control study. Am J Respir Crit Care Med. 2004;170(8):836-844.

2. Centers for Disease Control and Prevention. Vital signs: asthma prevalence, disease characteristics, and self-management education: United States, 2001-2009. MMWR Morb Mortal Wkly Rep. 2011;60(17): $547-552$.

3. Cisternas MG, Blanc PD, Yen IH, et al. A comprehensive study of the direct and indirect costs of adult asthma. J Allergy Clin Immunol. 2003;111:1212-1218.

4. Wenzel SE. Asthma: defining of the persistent adult phenotypes. Lancet. 2006;368:804-813.

5. Anderson GP. Endotyping asthma: new insights into key pathogenic mechanisms in a complex, heterogeneous disease. Lancet. 2008;372: $1107-1119$.

6. Lotvall J, Akdis CA, Bacharier LB, et al. Asthma endotypes: a new approach to classification of disease entities within the asthma syndrome. J Allergy Clin Immunol. 2011;127:355-360.

7. Simpson JL, Scott R, Boyle MJ, Gibson PG. Inflammatory subtypes in asthma: assessment and identification using induced sputum. Respirology. 2006;11:54-61.

8. Wenzel SE, Schwartz LB, Langmack EL, et al. Evidence that severe asthma can be divided pathologically into two inflammatory subtypes with distinct physiologic and clinical characteristics. Am J Respir Crit Care Med. 1999;160:1001-1008.

9. Amelink M, de Groot JC, de Nijs SB, et al. Severe adult-onset asthma: a distinct phenotype. J Allergy Clin Immunol. 2013;132:336-341.

10. Houston JC, De Navasquez S, Trounce JR. A clinical and pathological study of fatal cases of status asthmaticus. Thorax. 1953;8:207-213.

11. Bousquet J, Chanez P, Lacoste JY, et al. Eosinophilic inflammation in asthma. N Engl J Med. 1990;323:1033-1039.

12. Jatakanon A, Lim S, Barnes PJ. Changes in sputum eosinophils predict loss of asthma control. Am J Respir Crit Care Med. 2000;161:64-72.

13. Deykin A, Lazarus SC, Fahy JV, et al. Sputum eosinophil counts predict asthma control after discontinuation of inhaled corticosteroids. JAllergy Clin Immunol. 2005;115:720-727.

14. Meijer RJ, Postma DS, Kauffman HF, Arends LR, Koeter GH, Kerstjens HA. Accuracy of eosinophils and eosinophil cationic protein to predict steroid improvement in asthma. Clin Exp Allergy. 2002;32:1096-1103.
15. Berry M, Morgan A, Shaw DE, et al. Pathological features and inhaled corticosteroid response of eosinophilic and non-eosinophilic asthma. Thorax. 2007;62:1043-1049.

16. Haldar P, Brightling CE, Hargadon B, et al. Mepolizumab and exacerbations of refractory eosinophilic asthma. $N$ Engl J Med. 2009;360: 973-984.

17. Nair P, Pizzichini MM, Kjarsgaard M, et al. Mepolizumab for prednisone-dependent asthma with sputum eosinophilia. NEngl J Med. 2009;360:985-993.

18. Hamid Q, Tulic M. Immunobiology of asthma. Annu Rev Physiol. 2009;71:489-507.

19. Barrett NA, Austen KF. Innate cells and T helper 2 cell immunity in airway inflammation. Immunity. 2009;31:425-437.

20. Doherty T, Broide D. Cytokines and growth factors in airway remodeling in asthma. Curr Opin Immunol. 2007;19:676-680.

21. Garty BZ, Kosman E, Ganor E, et al. Emergency room visits of asthmatic children, relation to air pollution, weather, and airborne allergens. Ann Allergy Asthma Immunol. 1998;81:563-570.

22. D'Amato G, Cecchi L, Liccardi G. Thunderstorm-related asthma: not only grass pollen and spores. J Allergy Clin Immunol. 2008;121: $537-538$.

23. Holgate ST. Innate and adaptive immune responses in asthma. Nat Med. 2012;18:673-683.

24. Lee HC, Headley MB, Loo YM, et al. Thymic stromal lymphopoietin is induced by respiratory syncytial virus-infected airway epithelial cells and promotes a type 2 response to infection. J Allergy Clin Immunol. 2012;130:1187-1196. e5.

25. Ziegler SF. Thymic stromal lymphopoietin and allergic disease. J Allergy Clin Immunol. 2012;130:845-852.

26. Barnes PJ. The cytokine network in asthma and chronic obstructive pulmonary disease. J Clin Invest. 2008;118:3546-3556.

27. Wardlaw AJ, Brightling C, Green R, Woltmann G, Pavord I. Eosinophils in asthma and other allergic diseases. Br Med Bull. 2000; 56:985-1003.

28. Collins PD, Marleau S, Griffiths-Johnson DA, Jose PJ, Williams TJ. Cooperation between interleukin-5 and the chemokine eotaxin to induce eosinophil accumulation in vivo. $J$ Exp Med. 1995;182: 1169-1174.

29. Zietkowski Z, Tomasiak MM, Skiepko R, Bodzenta-Lukaszyk A. RANTES in exhaled breath condensate of stable and unstable asthma patients. Respir Med. 2008;102:1198-1202.

30. Broide DH, Paine MM, Firestein GS. Eosinophils express interleukin 5 and granulocyte macrophage-colony-stimulating factor mRNA at sites of allergic inflammation in asthmatics. J Clin Invest. 1992;90: 1414-1424.

31. Broide DH, Firestein GS. Endobronchial allergen challenge in asthma. Demonstration of cellular source of granulocyte macrophage colonystimulating factor by in situ hybridization. J Clin Invest. 1991;88: 1048-1053.

32. Davies D, Larbi K, Allen A, et al. VCAM-1 contributes to rapid eosinophil accumulation induced by the chemoattractants PAF and LTB4: evidence for basal expression of functional VCAM-1 in rat skin. Immunology. 1999;97:150-158.

33. Stirling RG, van Rensen EL, Barnes PJ, Chung KF. Interleukin-5 induces CD34(+) eosinophil progenitor mobilization and eosinophil CCR3 expression in asthma. Am J Respir Crit Care Med. 2001;164: 1403-1409.

34. Cho JY, Miller M, Baek KJ, et al. Inhibition of airway remodeling in IL-5-deficient mice. J Clin Invest. 2004;113:551-560.

35. Fahy JV. Eosinophilic and neutrophilic inflammation in asthma: insights from clinical studies. Proc Am Thorac Soc. 2009;6:256-259.

36. Green RH, Brightling CE, McKenna S, et al. Asthma exacerbations and sputum eosinophil counts: a randomised controlled trial. Lancet. 2002;360:1715-1721.

37. Woodruff PG, Khashayar R, Lazarus SC, et al. Relationship between airway inflammation, hyperresponsiveness, and obstruction in asthma. J Allergy Clin Immunol. 2001;108:753-758. 
38. Louis R, Lau LC, Bron AO, Roldaan AC, Radermecker M, Djukanovic R. The relationship between airways inflammation and asthma severity. Am J Respir Crit Care Med. 2000;161:9-16.

39. Porsbjerg C, Lund TK, Pedersen L, Backer V. Inflammatory subtypes in asthma are related to airway hyperresponsiveness to mannitol and exhaled NO. J Asthma. 2009;46:606-612.

40. Crimi E, Spanevello A, Neri M, Ind PW, Rossi GA, Brusasco V. Dissociation between airway inflammation and airway hyperresponsiveness in allergic asthma. Am J Respir Crit Care Med. 1998;157:4-9.

41. Miranda C, Busacker A, Balzar S, Trudeau J, Wenzel SE. Distinguishing severe asthma phenotypes: role of age at onset and eosinophilic inflammation. J Allergy Clin Immunol. 2004;113:101-108.

42. ten Brinke A, Zwinderman AH, Sterk PJ, Rabe KF, Bel EH. "Refractory" eosinophilic airway inflammation in severe asthma: effect of parenteral corticosteroids. Am J Respir Crit Care Med. 2004;170:601-605.

43. Thomson NC, Chaudhuri R. Why is eosinophilic bronchitis not asthma? Am J Respir Crit Care Med. 2004;170:4-5.

44. Brightling CE, Bradding P, Symon FA, Holgate ST, Wardlaw AJ, Pavord ID. Mast-cell infiltration of airway smooth muscle in asthma. $N$ Engl J Med. 2002;346:1699-1705.

45. Kanazawa H, Nomura S, Yoshikawa J. Role of microvascular permeability on physiologic differences in asthma and eosinophilic bronchitis. Am J Respir Crit Care Med. 2004;169:1125-1130.

46. Frick WE, Sedgwick JB, Busse WW. The appearance of hypodense eosinophils in antigen-dependent late phase asthma. Am Rev Respir Dis. 1989;139:1401-1406.

47. Ulrik CS. Peripheral eosinophil counts as a marker of disease activity in intrinsic and extrinsic asthma. Clin Exp Allergy. 1995;25:820-827.

48. Hastie AT, Moore WC, Li H, et al. Biomarker surrogates do not accurately predict sputum eosinophil and neutrophil percentages in asthmatic subjects. J Allergy Clin Immunol. 2013;132:72-80.

49. D’Silva L, Cook RJ, Allen CJ, Hargreave FE, Parameswaran K. Changing pattern of sputum cell counts during successive exacerbations of airway disease. Respir Med. 2007;101:2217-2220.

50. Good JT Jr, Kolakowski CA, Groshong SD, Murphy JR, Martin RJ. Refractory asthma: importance of bronchoscopy to identify phenotypes and direct therapy. Chest. 2011;141:599-606.

51. Silkoff PE, Lent AM, Busacker AA, et al. Exhaled nitric oxide identifies the persistent eosinophilic phenotype in severe refractory asthma. J Allergy Clin Immunol. 2005;116:1249-1255.

52. Mahr TA, Malka J, Spahn JD. Inflammometry in pediatric asthma: a review of fractional exhaled nitric oxide in clinical practice. Allergy Asthma Proc. 2013;34:210-219.

53. Barnes PJ, Dweik RA, Gelb AF, et al. Exhaled nitric oxide in pulmonary diseases: a comprehensive review. Chest. 2010;138:682-692.

54. Smith AD, Cowan JO, Brassett KP, Herbison GP, Taylor DR. Use of exhaled nitric oxide measurements to guide treatment in chronic asthma. N Engl J Med. 2005;352:2163-2173.

55. Tseliou E, Bessa V, Hillas G, et al. Exhaled nitric oxide and exhaled breath condensate $\mathrm{pH}$ in severe refractory asthma. Chest. 2010;138: 107-113.

56. Blanchard C, Mingler MK, McBride M, et al. Periostin facilitates eosinophil tissue infiltration in allergic lung and esophageal responses. Mucosal Immunol. 2008;1:289-296.

57. Ouyang G, Liu M, Ruan K, Song G, Mao Y, Bao S. Upregulated expression of periostin by hypoxia in non-small-cell lung cancer cells promotes cell survival via the Akt/PKB pathway. Cancer Lett. 2009;281:213-219.

58. Jia G, Erickson RW, Choy DF, et al. Periostin is a systemic biomarker of eosinophilic airway inflammation in asthmatic patients. J Allergy Clin Immunol. 2012;130:647-654. e10.

59. Corren J, Lemanske RF, Hanania NA, et al. Lebrikizumab treatment in adults with asthma. N Engl J Med. 2011;365:1088-1098.

60. Masuoka M, Shiraishi H, Ohta S, et al. Periostin promotes chronic allergic inflammation in response to Th2 cytokines. J Clin Invest. 2012;122:2590-2600.
61. Gordon ED, Sidhu SS, Wang ZE, et al. A protective role for periostin and TGF-beta in IgE-mediated allergy and airway hyperresponsiveness. Clin Exp Allergy. 2012;42:144-155.

62. Kulkarni NS, Hollins F, Sutcliffe A, et al. Eosinophil protein in airway macrophages: a novel biomarker of eosinophilic inflammation in patients with asthma. J Allergy Clin Immunol. 2010;126:61-69. e3.

63. Barnes PJ. Severe asthma: advances in current management and future therapy. J Allergy Clin Immunol. 2012;129:48-59.

64. Irusen E, Matthews JG, Takahashi A, Barnes PJ, Chung KF, Adcock IM. p38 Mitogen-activated protein kinase-induced glucocorticoid receptor phosphorylation reduces its activity: role in steroid-insensitive asthma. J Allergy Clin Immunol. 2002;109:649-657.

65. Maneechotesuwan K, Xin Y, Ito K, et al. Regulation of Th2 cytokine genes by $\mathrm{p} 38$ MAPK-mediated phosphorylation of GATA-3. J Immunol. 2007;178:2491-2498.

66. Cuenda A, Rousseau S. p38 MAP-kinases pathway regulation, function and role in human diseases. Biochim Biophys Acta. 2007;1773: $1358-1375$.

67. Barnes PJ, Adcock IM. Glucocorticoid resistance in inflammatory diseases. Lancet. 2009;373:1905-1917.

68. MizueY, Ghani S, Leng L, et al. Role for macrophage migration inhibitory factor in asthma. Proc Natl Acad Sci U S A. 2005;102:14410-14415.

69. Pelaia G, Vatrella A, Maselli R. The potential of biologics for the treatment of asthma. Nat Rev Drug Discov. 2012;11:958-972.

70. Saini SS, MacGlashan DW Jr, Sterbinsky SA, et al. Down-regulation of human basophil IgE and FC epsilon RI alpha surface densities and mediator release by anti-IgE-infusions is reversible in vitro and in vivo. J Immunol. 1999;162:5624-5630.

71. Humbert M, Beasley R, Ayres J, et al. Benefits of omalizumab as add-on therapy in patients with severe persistent asthma who are inadequately controlled despite best available therapy (GINA 2002 step 4 treatment): INNOVATE. Allergy. 2005;60:309-316.

72. Ayres JG, Higgins B, Chilvers ER, Ayre G, Blogg M, Fox H. Efficacy and tolerability of anti-immunoglobulin E therapy with omalizumab in patients with poorly controlled (moderate-to-severe) allergic asthma. Allergy. 2004;59:701-708.

73. Vignola AM, Humbert M, Bousquet J, et al. Efficacy and tolerability of anti-immunoglobulin $\mathrm{E}$ therapy with omalizumab in patients with concomitant allergic asthma and persistent allergic rhinitis: SOLAR. Allergy. 2004;59:709-717.

74. Busse W, Corren J, Lanier BQ, et al. Omalizumab, anti-IgE recombinant humanized monoclonal antibody, for the treatment of severe allergic asthma. J Allergy Clin Immunol. 2001;108:184-190.

75. Soler M, Matz J, Townley R, et al. The anti-IgE antibody omalizumab reduces exacerbations and steroid requirement in allergic asthmatics. Eur Respir J. 2001;18:254-261.

76. Lanier BQ, Corren J, Lumry W, Liu J, Fowler-Taylor A, Gupta N. Omalizumab is effective in the long-term control of severe allergic asthma. Ann Allergy Asthma Immunol. 2003;91:154-159.

77. Holgate ST, Chuchalin AG, Hebert J, et al. Efficacy and safety of a recombinant anti-immunoglobulin $\mathrm{E}$ antibody (omalizumab) in severe allergic asthma. Clin Exp Allergy. 2004;34:632-638.

78. Bousquet J, Rabe K, Humbert M, et al. Predicting and evaluating response to omalizumab in patients with severe allergic asthma. Respir Med. 2007;101:1483-1492.

79. Noga O, Hanf G, Brachmann I, et al. Effect of omalizumab treatment on peripheral eosinophil and T-lymphocyte function in patients with allergic asthma. J Allergy Clin Immunol. 2006;117:1493-1499.

80. Djukanovic R, Wilson SJ, Kraft M, et al. Effects of treatment with anti-immunoglobulin E antibody omalizumab on airway inflammation in allergic asthma. Am J Respir Crit Care Med. 2004;170:583-593.

81. Noga O, Hanf G, Kunkel G. Immunological and clinical changes in allergic asthmatics following treatment with omalizumab. Int Arch Allergy Immunol. 2003;131:46-52.

82. Milgrom H, Fick RB Jr, Su JQ, et al. Treatment of allergic asthma with monoclonal anti-IgE antibody. rhuMAb-E25 Study Group. $N$ Engl $J$ Med. 1999;341:1966-1973. 
83. Holgate S, Casale T, Wenzel S, Bousquet J, Deniz Y, Reisner C. The anti-inflammatory effects of omalizumab confirm the central role of IgE in allergic inflammation. J Allergy Clin Immunol. 2005;115: $459-465$.

84. Chand HS, Schuyler M, Joste N, et al. Anti-IgE therapy results in decreased myeloid dendritic cells in asthmatic airways. J Allergy Clin Immunol. 2010;125:1157-1158. e5.

85. Kaya H, Gumus S, Ucar E, et al. Omalizumab as a steroid-sparing agent in chronic eosinophilic pneumonia. Chest. 2012;142:513-516.

86. Hamid Q, Azzawi M, Ying S, et al. Expression of mRNA for interleukin-5 in mucosal bronchial biopsies from asthma. J Clin Invest. 1991;87:1541-1546.

87. Humbert M, Corrigan CJ, Kimmitt P, Till SJ, Kay AB, Durham SR. Relationship between IL-4 and IL-5 mRNA expression and disease severity in atopic asthma. Am J Respir Crit Care Med. 1997;156: 704-708.

88. Garlisi CG, Kung TT, Wang P, et al. Effects of chronic antiinterleukin-5 monoclonal antibody treatment in a murine model of pulmonary inflammation. Am J Respir Cell Mol Biol. 1999;20: $248-255$.

89. Gnanakumaran G, Babu KS. Technology evaluation: mepolizumab, GlaxoSmithKline. Curr Opin Mol Ther. 2003;5:321-325.

90. Menzies-Gow A, Flood-Page P, Sehmi R, et al. Anti-IL-5 (mepolizumab) therapy induces bone marrow eosinophil maturational arrest and decreases eosinophil progenitors in the bronchial mucosa of atopic asthmatics. J Allergy Clin Immunol. 2003;111:714-719.

91. Kips JC, O’Connor BJ, Langley SJ, et al. Effect of SCH55700, a humanized anti-human interleukin-5 antibody, in severe persistent asthma: a pilot study. Am J Respir Crit Care Med. 2003;167:1655-1659.

92. Leckie MJ, ten Brinke A, Khan J, et al. Effects of an interleukin-5 blocking monoclonal antibody on eosinophils, airway hyper-responsiveness, and the late asthmatic response. Lancet. 2000;356:2144-2148.

93. Flood-Page P, Swenson C, Faiferman I, et al. A study to evaluate safety and efficacy of mepolizumab in patients with moderate persistent asthma. Am J Respir Crit Care Med. 2007;176:1062-1071.

94. Castro M, Mathur S, Hargreave F, et al. Reslizumab for poorly controlled, eosinophilic asthma: a randomized, placebo-controlled study. Am J Respir Crit Care Med. 2011;184:1125-1132.

95. Busse WW, Katial R, Gossage D, et al. Safety profile, pharmacokinetics, and biologic activity of MEDI-563, an anti-IL-5 receptor alpha antibody, in a phase I study of subjects with mild asthma. J Allergy Clin Immunol. 2010;125:1237-1244. e2.

96. Laviolette M, Gossage DL, Gauvreau G, et al. Effects of benralizumab on airway eosinophils in asthmatic patients with sputum eosinophilia. J Allergy Clin Immunol. 2013;132:1086-1096. e5.

97. Ingram JL, Kraft M. IL-13 in asthma and allergic disease: asthma phenotypes and targeted therapies. JAllergy Clin Immunol. 2012;130: 829-842.

98. Hart TK, Blackburn MN, Brigham-Burke M, et al. Preclinical efficacy and safety of pascolizumab (SB 240683): a humanized anti-interleukin-4 antibody with therapeutic potential in asthma. Clin Exp Immunol. 2002;130:93-100.

99. Henderson WR Jr, Chi EY, Maliszewski CR. Soluble IL-4 receptor inhibits airway inflammation following allergen challenge in a mouse model of asthma. J Immunol. 2000;164:1086-1095.

100. Borish LC, Nelson HS, Corren J, et al. Efficacy of soluble IL-4 receptor for the treatment of adults with asthma. J Allergy Clin Immunol. 2001;107:963-970.

101. Wenzel S, Wilbraham D, Fuller R, Getz EB, Longphre M. Effect of an interleukin-4 variant on late phase asthmatic response to allergen challenge in asthmatic patients: results of two phase 2a studies. Lancet. 2007;370:1422-1431.
102. Wenzel S, Ford L, Pearlman D, et al. Dupilumab in persistent asthma with elevated eosinophil levels. $N$ Engl J Med. 2013;368: 2455-2466.

103. Pope SM, Brandt EB, Mishra A, et al. IL-13 induces eosinophil recruitment into the lung by an IL-5- and eotaxin-dependent mechanism. J Allergy Clin Immunol. 2001;108:594-601.

104. Spahn JD, Szefler SJ, Surs W, Doherty DE, Nimmagadda SR, Leung DY. A novel action of IL-13: induction of diminished monocyte glucocorticoid receptor-binding affinity. J Immunol. 1996;157:2654-2659.

105. Yang G, Volk A, Petley T, et al. Anti-IL-13 monoclonal antibody inhibits airway hyperresponsiveness, inflammation and airway remodeling. Cytokine. 2004;28:224-232.

106. Bree A, Schlerman FJ, Wadanoli M, et al. IL-13 blockade reduces lung inflammation after Ascaris suum challenge in cynomolgus monkeys. J Allergy Clin Immunol. 2007;119:1251-1257.

107. Gauvreau GM, Boulet LP, Cockcroft DW, et al. Effects of interleukin-13 blockade on allergen-induced airway responses in mild atopic asthma. Am J Respir Crit Care Med. 2011;183: 1007-1014.

108. Piper E, Brightling C, Niven R, et al. A phase II placebo-controlled study of tralokinumab in moderate-to-severe asthma. Eur Respir J. 2013;41:330-338.

109. Tamachi T, Maezawa Y, Ikeda K, et al. IL-25 enhances allergic airway inflammation by amplifying a TH2 cell-dependent pathway in mice. $J$ Allergy Clin Immunol. 2006;118:606-614.

110. Fujita J, Kawaguchi M, Kokubu F, et al. Interleukin-33 induces interleukin-17F in bronchial epithelial cells. Allergy. 2012;67: 744-750.

111. Shi L, Leu SW, Xu F, et al. Local blockade of TSLP receptor alleviated allergic disease by regulating airway dendritic cells. Clin Immunol. 2008;129:202-210.

112. Amgen. Double-blind, Multiple Dose Study in Subjects With Mild Atopic Asthma. Available from: http://clinicaltrials.gov/show/ NCT01405963. NLM identifier: NCT01405963. Accessed February 3, 2014.

113. Gauvreau GM, Boulet LP, Cockcroft DW, et al. Antisense therapy against CCR3 and the common beta chain attenuates allergeninduced eosinophilic responses. Am J Respir Crit Care Med. 2008;177:952-958.

114. Krinner EM, Raum T, Petsch S, et al. A human monoclonal IgG1 potently neutralizing the pro-inflammatory cytokine GM-CSF. Mol Immunol. 2007;44:916-925.

115. Kiwamoto T, Kawasaki N, Paulson JC, Bochner BS. Siglec-8 as a drugable target to treat eosinophil and mast cell-associated conditions. Pharmacol Ther. 2012;135:327-336.

116. Wenzel SE, Barnes PJ, Bleecker ER, et al. A randomized, double-blind, placebo-controlled study of tumor necrosis factor-alpha blockade in severe persistent asthma. Am J Respir Crit Care Med. 2009;179:549-558.

117. Holgate ST, Noonan M, Chanez P, et al. Efficacy and safety of etanercept in moderate-to-severe asthma: a randomised, controlled trial. Eur Respir J. 2011;37:1352-1359.

118. Castro M, Musani AI, Mayse ML, Shargill NS. Bronchial thermoplasty: a novel technique in the treatment of severe asthma. Ther Adv Respir Dis. 2010;4:101-116.

119. Castro M, Rubin AS, Laviolette M, et al. Effectiveness and safety of bronchial thermoplasty in the treatment of severe asthma: a multicenter, randomized, double-blind, sham-controlled clinical trial. Am J Respir Crit Care Med. 2012;181:116-124.

120. Thomson NC, Rubin AS, Niven RM, et al. Long-term ( 5 year) safety of bronchial thermoplasty: Asthma Intervention Research (AIR) trial. BMC Pulm Med. 2011;11:8. 
Journal of Asthma and Allergy

\section{Publish your work in this journal}

The Journal of Asthma and Allergy is an international, peer-reviewed open-access journal publishing original research, reports, editorials and commentaries on the following topics: Asthma; Pulmonary physiology; Asthma related clinical health; Clinical immunology and the immunological basis of disease; Pharmacological interventions and

new therapies. Issues of patient safety and quality of care will also be considered. The manuscript management system is completely online and includes a very quick and fair peer-review system, which is all easy to use. Visit http://www.dovepress.com/testimonials.php to read real quotes from published authors.

Submit your manuscript here: http://www.dovepress.com/journal-of-asthma-and-allergy-journal 